\title{
Interaction of Candida albicans with Neutrophils: Effect of Phenotypic Changes in Yeast Cell-surface Composition
}

\author{
By JOHN G. HOUSTON AND L. JULIA DOUGLAS* \\ Department of Microbiology, University of Glasgow, Alexander Stone Building, Garscube Estate, \\ Bearsden, Glasgow G61 1QH, UK
}

(Received 21 September 1988; revised 19 January 1989; accepted 1 March 1989)

\begin{abstract}
The susceptibility of four strains of Candida albicans to phagocytosis and intracellular killing by rabbit peritoneal neutrophils was investigated. Two of the strains, isolated from active infections, were known to synthesize a surface layer of mannoprotein fibrils in response to growth on 500 mM-galactose; the other strains, from asymptomatic carriers, lacked this capability. The presence of serum opsonins greatly enhanced phagocytosis of all four strains and, following opsonization, phagocytosis of an infective strain was equally rapid after growth on either $500 \mathrm{~mm}$-galactose or $50 \mathrm{~mm}$-glucose. In the absence of opsonins, galactose-grown infective strains were phagocytosed faster than either glucose-grown infective strains or galactose-grown carrier strains. These differences in phagocytic uptake were paralleled by differences in neutrophil chemiluminescence response. Intracellular killing of galactose-grown infective strains was only half that of glucose-grown infective strains or galactose-grown carrier strains after incubation for $60 \mathrm{~min}$. Pretreatment of neutrophils with extracellular polymeric material, which contains the surface fibrils, completely inhibited intracellular killing. These results indicate that production of the fibrillar layer promotes yeast virulence by increasing resistance to intracellular killing, although it may enhance phagocytosis in locations where opsonic activity is poor.
\end{abstract}

\section{INTRODUCTION}

Polymorphonuclear leucocytes (neutrophils) play a major role in host defence against the opportunistic yeast pathogen, Candida albicans (Rogers \& Balish, 1980), and there have been many reports on interactions between $C$. albicans and human or animal neutrophils in vitro (reviewed by Odds, 1988). Some of these studies focused on the relative susceptibilities of different strains (Richardson \& Smith, 1981) or morphological forms (Scherwitz \& Martin, 1979; Cockayne \& Odds, 1984) of the fungus to phagocytosis and intracellular killing. Others concentrated on the biochemical processes involved and established that the myeloperoxidase$\mathrm{H}_{2} \mathrm{O}_{2}$-halide oxidative system is the principal candidacidal mechanism within neutrophils (Lehrer \& Cline, 1969; Diamond et al., 1980; Wagner et al., 1986). There have also been a number of investigations on the effect of yeast cell-wall mannoprotein on neutrophil and macrophage function (Wright et al., 1981, 1983; Okawa et al., 1986; Kolotila et al., 1987). Wright et al. (1983), for example, showed that isolated mannoprotein (mannan) can bind to myeloperoxidase and thereby inhibit the candidacidal activity of neutrophils in vitro.

Previous work from this laboratory has demonstrated that growth of $C$. albicans in medium containing high concentrations of certain sugars, particularly galactose, can stimulate the production of a fibrillar mannoprotein layer on the yeast surface (McCourtie \& Douglas, 1981, 1985). The fibrils, which can be recovered as extracellular polymeric material (EP) from culture supernatants, appear to enhance both yeast adhesion to epithelial cells and the virulence of the

Abbreviations: EP, extracellular polymeric material; HBS, HEPES buffered salt solution. 
organism for mice (McCourtie \& Douglas, 1984). Synthesis of the surface layer is straindependent; of nine strains of $C$. albicans tested, seven (isolated from active infections) showed considerable aptitude for this type of cell-surface modification, while two (obtained from asymptomatic carriers) did not. Other less pathogenic Candida species, as well as the nonpathogenic yeast Saccharomyces cerevisiae, also seem unable to synthesize the fibrillar layer (Critchley \& Douglas, 1985).

Although the involvement of mannoprotein fibrils in C. albicans adhesion has been described (Critchley \& Douglas, $1987 a, b$ ), the mechanism by which their synthesis enhances yeast virulence following intravenous injection has not been established. In the present study, we investigated the possibility that the fibrillar surface layer affords the yeast some protection against phagocytosis or intracellular killing by neutrophils. Both infective and carrier strains of C. albicans were examined under conditions which promote (growth on $500 \mathrm{~mm}$-galactose) or inhibit (growth on $50 \mathrm{~mm}$-glucose) fibril production in infective strains. The effect of isolated EP on neutrophil function was also evaluated.

\section{METHODS}

Organisms. Four strains of C. albicans were used in this study. Strains GDH 2346 (NCYC 1467) and GDH 2023 (NCYC 1468) were isolated at Glasgow Dental Hospital from patients with denture stomatitis. Strains GRI 681 (NCYC 1472) and GRI 682 (NCYC 1473) were obtained from routine cervical smears taken from asymptomatic women at Glasgow Royal Infirmary. All organisms were maintained on slopes of Sabouraud dextrose agar (Difco) and subcultured monthly. Every two months, cultures were replaced by new ones freshly grown from freeze-dried stocks.

Growth conditions. The yeasts were grown at $37^{\circ} \mathrm{C}$ with shaking, in yeast nitrogen base medium (Difco) containing $50 \mathrm{~mm}$-glucose or $500 \mathrm{~mm}$-galactose as described by McCourtie \& Douglas (1981). Organisms were harvested after $24 \mathrm{~h}$ (stationary growth phase) and washed twice in HEPES buffered salt solution (HBS), containing $\left(\mathrm{g}^{-1}\right)$ : $\mathrm{NaCl}, 8 \cdot 0 ; \mathrm{KCl}, 0.40 ; \mathrm{MgCl}_{2} .6 \mathrm{H}_{2} \mathrm{O}, 0.20 ; \mathrm{CaCl}_{2}, 0.14$; glucose, $1.0 ; \mathrm{HEPES}, 2.39$ (pH 7.4).

Opsonization of yeasts. Opsonization was achieved by incubating yeasts with $10 \%(\mathrm{v} / \mathrm{v})$ normal rabbit serum at $37^{\circ} \mathrm{C}$ for $30 \mathrm{~min}$. The serum was stored at $-70^{\circ} \mathrm{C}$.

Preparation of rabbit neutrophils. Peritoneal neutrophils were obtained from female New Zealand white rabbits. Saline $(500 \mathrm{ml})$, containing $0.1 \%$ oyster glycogen (Sigma), was injected intraperitoneally and peritoneal exudate collected $4 \mathrm{~h}$ later (Lackie, 1977). The exudate was stored at $4{ }^{\circ} \mathrm{C}$ and used within $2 \mathrm{~d}$ of isolation. Before use, the cells were washed once in divalent-cation-free HBS, containing $1 \mathrm{mM}-E D T A$, and then in normal HBS. Contaminating erythrocytes were lysed after the first wash by brief exposure (5s) to distilled water. To obtain a homogeneous population of single cells and to remove any fibrin clots, the neutrophils were passed through a $10 \mu \mathrm{m}$ Nitrex filter (Plastok). Finally, cell numbers were standardized by counting with a haemocytometer. All neutrophil suspensions were more than $95 \%$ pure and cell viability was greater than $95 \%$ as determined by trypan blue exclusion.

Chemiluminescence measurements. Luminol-dependent chemiluminescence of neutrophils was measured (in $\mathrm{mV}$ ) at $37^{\circ} \mathrm{C}$ using an automated luminometer (Wallac-LKB 1251) connected to a microcomputer. Each assay mixture contained $10^{6}$ neutrophils, $10^{7}$ yeasts and $10^{-5} \mathrm{M}$-luminol in a total volume of $0.7 \mathrm{ml}$; this Candida to neutrophil ratio of $10: 1$ produced optimal chemiluminescence response (results not shown). Neutrophils were preincubated at $37^{\circ} \mathrm{C}$ for $20 \mathrm{~min}$ before addition of the yeasts. At the start of the assay, luminol $(70 \mu \mathrm{l})$ was added by an automatic dispenser. Luminol (5-amino-2,3-dihydro-1,4-phthalazinedione; Sigma) was first prepared as a 0.01 M solution in dimethyl sulphoxide and then diluted 100 -fold in $\mathrm{HBS}$ and stored at $-20^{\circ} \mathrm{C}$ until use. All mixtures were assayed in triplicate. Control mixtures in which neutrophils were incubated without yeasts, in the presence or absence of rabbit serum, produced a low, background, chemiluminescence response.

Phagocytosis of yeasts. The method used was essentially that of Leijh et al. (1977). Yeasts $\left(10^{7} \mathrm{ml}^{-1}\right.$ in HBS; $\left.1 \mathrm{ml}\right)$ were incubated with $1 \mathrm{ml}$ neutrophil suspension $\left(10^{7}\right.$ cells $\left.\mathrm{ml}^{-1}\right)$ and $0.2 \mathrm{ml}$ rabbit serum (opsonized conditions) or $0.2 \mathrm{ml} \mathrm{HBS}$ (unopsonized conditions) in plastic bijoux bottles at $37^{\circ} \mathrm{C}$ under gentle rotation ( 50 r.p.m.) for $60 \mathrm{~min}$. This 1:1 ratio of Candida to neutrophils was found to be optimal for phagocytosis studies (results not shown). At intervals, portions of suspension $(0.1 \mathrm{ml})$ were removed and diluted with $0.1 \mathrm{ml} \mathrm{HBS}$. The number of extracellular yeasts lying totally free in the suspension was then determined using a haemocytometer. [Attached (but unphagocytosed) yeasts were never observed at $37^{\circ} \mathrm{C}$ and the number of extracellular yeasts was therefore a valid measure of phagocytosis.] The figure obtained was used to calculate, by subtraction, the percentage of yeasts which had been phagocytosed. All phagocytosis experiments were repeated a minimum of three times. Control incubation mixtures containing yeasts and serum but no neutrophils indicated that the number of yeast cells 
remained constant over the $60 \mathrm{~min}$ period. Clumping of yeasts or formation of germ tubes was not observed during the assay.

Yeast binding to neutrophils. This was measured at $4{ }^{\circ} \mathrm{C}$, a temperature at which phagocytosis (of either opsonized or unopsonized yeasts) was inhibited by more than $90 \%$. Candida suspension $\left(2 \times 10^{7}\right.$ yeasts $\left.\mathrm{ml}^{-1} ; 1 \mathrm{ml}\right)$ was incubated with $1 \mathrm{ml}$ of neutrophil suspension $\left(10^{7}\right.$ cells $\left.\mathrm{ml}^{-1}\right)$ and $0.2 \mathrm{ml}$ rabbit serum (opsonized conditions)

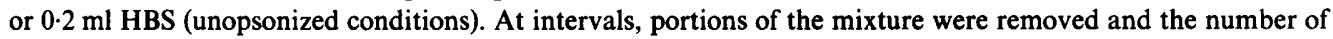
yeasts attached to 100 neutrophils was determined using a haemocytometer.

Intracellular killing of yeasts. Assay mixtures were prepared and incubated as described for phagocytosis experiments. At intervals during incubation, portions of the suspension $(0 \cdot 1 \mathrm{ml})$ were removed, added to $0 \cdot 1 \mathrm{ml}$ of filter-sterilized $1 \%$ saponin with thorough mixing, and left at room temperature for $5 \mathrm{~min}$ to allow lysis of the neutrophils and release of internalized yeasts. Duplicate serial dilutions of the lysate (in HBS) were plated on Sabouraud dextrose agar. After incubation of the plates at $37^{\circ} \mathrm{C}$ for $18 \mathrm{~h}$, the number of c.f.u. was determined as a measure of the number of viable Candida cells present. Intracellular killing was expressed as the percentage decrease in c.f.u. as compared with the initial value for the yeast suspension. Control incubation mixtures showed that yeast viability was unaffected by saponin or serum during the assay period.

Pretreatment of neutrophils with EP. In some experiments, neutrophils were pretreated with EP prepared from culture supernatants of $C$. albicans GDH 2346 as described by Critchley \& Douglas (1987a). For assays of phagocytosis and intracellular killing, neutrophils $(1 \mathrm{ml})$ were incubated at $37^{\circ} \mathrm{C}$ for 30 min with EP $\left(10 \mathrm{mg} \mathrm{ml}^{-1}\right)$ prior to addition of Candida suspension. Similarly, for chemiluminescence assays, neutrophils were incubated with EP ( $\left.10 \mathrm{mg} \mathrm{ml}^{-1}\right)$ at $37^{\circ} \mathrm{C}$ for $30 \mathrm{~min}$ before the addition of yeasts and injection of luminol. In control mixtures, neutrophils were pretreated wtih HBS instead of EP. Viability of the neutrophils was unaffected by pretreatment with EP as determined by trypan blue exclusion.

\section{RESULTS}

\section{Phagocytosis of C. albicans}

Phagocytosis of opsonized C. albicans GDH 2346 by rabbit peritoneal neutrophils was much greater than that of unopsonized yeasts of the same strain (Fig. 1). After $15 \mathrm{~min}$, less than $25 \%$ of the opsonized organisms remained extracellular to the neutrophils whereas over $90 \%$ of the unopsonized yeasts were unphagocytosed. The rates of phagocytosis of opsonized organisms grown on different carbon sources were essentially similar. However, with unopsonized yeasts, organisms grown in medium containing $500 \mathrm{~mm}$-galactose were phagocytosed more extensively than those grown on 50 mM-glucose (Fig. 1). Yeasts attached to the neutrophil surface were not observed in any of these assays.

Other strains of $C$. albicans were also examined for their sensitivity to phagocytosis after growth in high-galactose medium. With all of these strains, opsonized yeasts were phagocytosed rapidly and to a similar extent (Table 1). Unopsonized organisms were phagocytosed less rapidly, and strains isolated from active infections (GDH 2346 and GDH 2023) appeared to be more susceptible to phagocytosis than those (GRI 681 and GRI 682) obtained from asymptomatic carriers.

\section{Yeast binding to neutrophils}

Incubation at low temperature has been used to dissociate the attachment and ingestion phases of phagocytosis of another yeast pathogen, Cryptococcus neoformans, in vitro (Kozel \&

Table 1. Phagocytosis of C. albicans strains grown in medium containing $500 \mathrm{~mm}$-galactose as the carbon source

Values shown are means ( \pm SEM) from 3-6 separate experiments.

Percentage of yeasts remaining extracellular after $60 \mathrm{~min}$

Strain

$\overbrace{\text { Opsonized Unopsonized }}$

GDH 2346

GDH 2023

GDH 681

GDH 682

$\begin{array}{ll}3 \cdot 5 \pm 0.5 & 71 \pm 2 \\ 2 \cdot 8 \pm 0.4 & 65 \pm 3 \\ 3 \cdot 2 \pm 0.6 & 93 \pm 2 \\ 2 \cdot 9 \pm 0.4 & 85 \pm 2\end{array}$




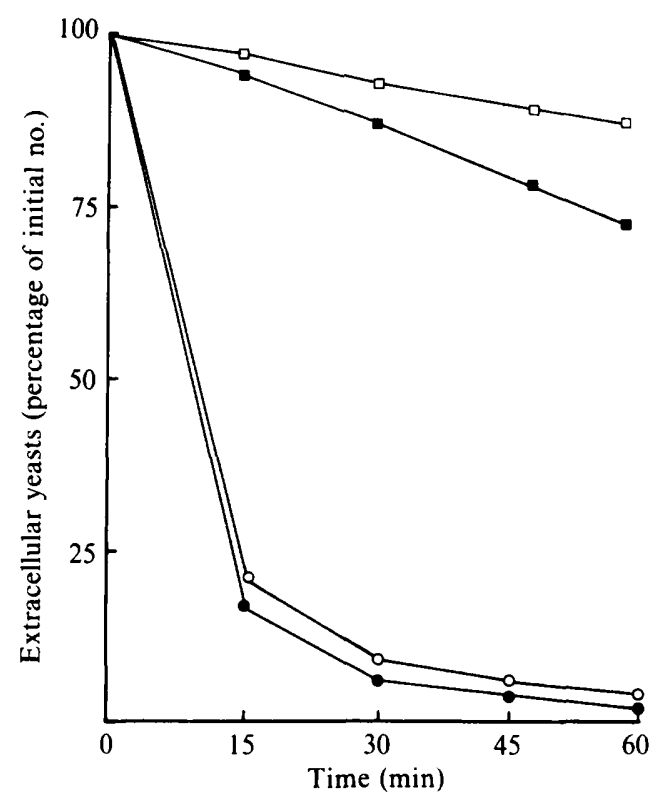

Fig. 1. Phagocytosis of opsonized $(O, \bullet)$ and unopsonized $(\square, \square)$ C. albicans GDH 2346 after growth in medium containing either $50 \mathrm{~mm}$-glucose $(O, \square)$ or $500 \mathrm{mM}$-galactose $(\boldsymbol{O}, \square)$ as the carbon source. The results shown are representative of those obtained in at least three separate experiments.

Mastroianni, 1976). In the present study, ingestion of opsonized C. albicans GDH 2346 was severely inhibited at $4{ }^{\circ} \mathrm{C}$, with an apparent uptake of less than $10 \%$ after $60 \mathrm{~min}$, as compared with more than $95 \%$ uptake at $37^{\circ} \mathrm{C}$ (results not shown). Candida attachment to neutrophils was measurable at $4{ }^{\circ} \mathrm{C}$, and bound yeasts probably accounted for most of those reckoned, by the phagocytosis assay, to be ingested at this temperature. There was no difference in neutrophil binding between opsonized yeasts grown on $50 \mathrm{~mm}$-glucose as a carbon source $(8.6 \%)$ and those grown on $500 \mathrm{mm-galactose}(9.1 \%)$. With unopsonized organisms, galactose-grown yeasts consistently bound in higher numbers $(5.5 \%)$ than glucose-grown yeasts $(3.5 \%)$, although the difference at this low level of attachment was not statistically significant.

\section{Intracellular killing of yeasts by neutrophils}

The ability of yeasts to resist intracellular killing was investigated using opsonized organisms only, because of the relatively poor uptake of unopsonized yeasts by neutrophils. Survival was dependent both on the strain of $C$. albicans and on the nature of the growth medium (Table 2). Growth of strain GDH 2346 on 500 mM-galactose produced yeasts with an enhanced capacity for survival; after incubation with neutrophils for $60 \mathrm{~min}$, these organisms had a viability twofold greater than that of yeasts grown on $50 \mathrm{~mm}$-glucose. A similarly increased resistance to intracellular killing was observed with galactose-grown yeasts of strain GDH 2023. Growth of the two carrier strains (GRI 681 and GRI 682) on galactose, on the other hand, produced no such increase; these organisms had a survival rate comparable with that of glucose-grown yeasts of strain GDH 2346 (Table 2).

\section{Chemiluminescence studies}

Stimulation of neutrophil phagocytic activity by yeasts was also investigated by measuring the generation of luminol-enhanced chemiluminescence (Allen \& Loose, 1976). The chemiluminescence response of neutrophils to opsonized $C$. albicans GDH 2346 was much greater and more rapid than that to unopsonized organisms (Fig. $2 a, b$ ). There was essentially no difference in the response elicited by opsonized yeasts grown on different carbon sources (Fig. $2 a$ ). However, with unopsonized organisms (Fig. $2 b$ ), $500 \mathrm{~mm}$-galactose-grown yeasts produced a 

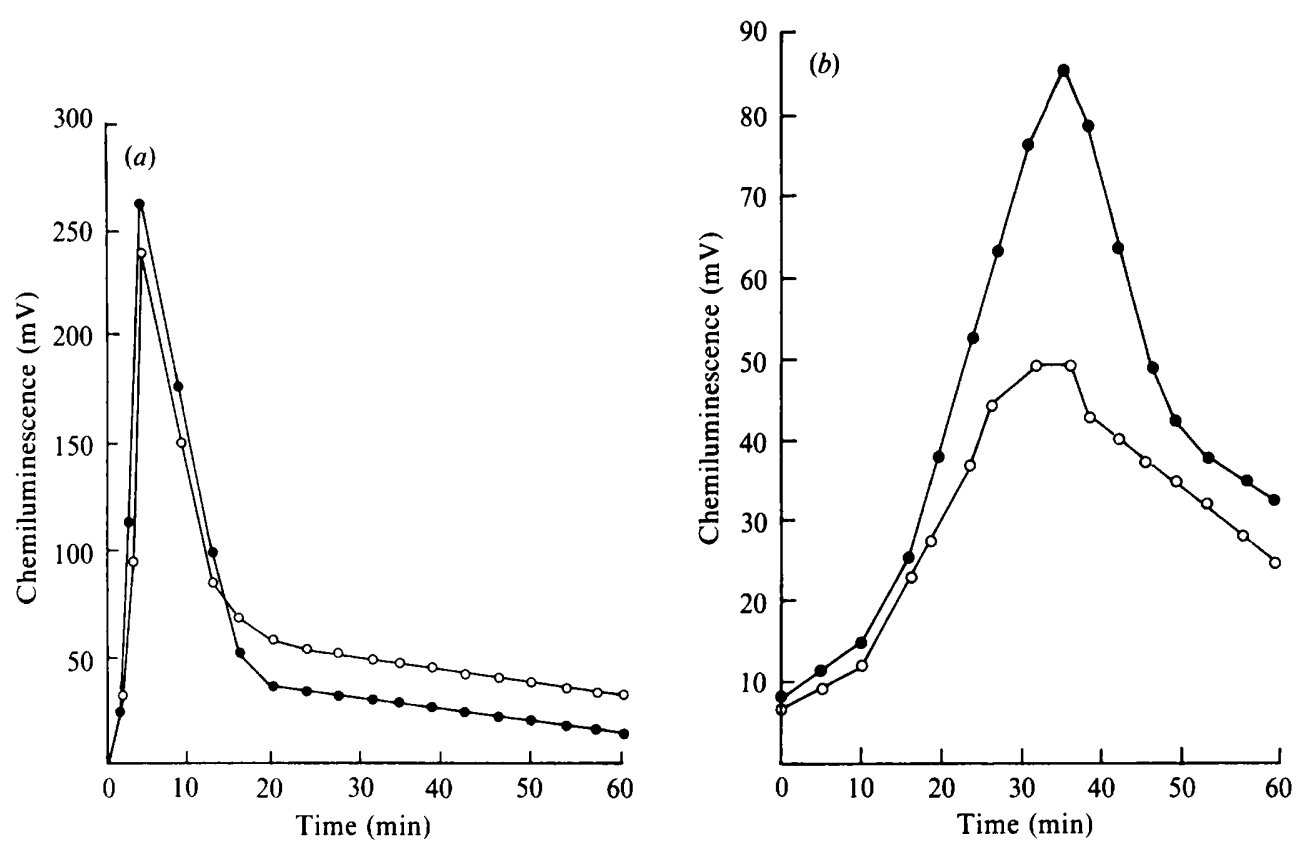

Fig. 2. Luminol-enhanced chemiluminescence emitted by neutrophils stimulated with opsonized $(a)$ or unopsonized (b) C. albicans GDH 2346 grown in medium containing $500 \mathrm{~mm}$-galactose (O) or $50 \mathrm{~mm}$ glucose $(O)$ as the carbon source. The data represent mean values from triplicate assays, and are typical of those obtained in at least three separate experiments.

Table 2. Intracellular killing of C. albicans strains by neutrophils after growth of the yeasts in medium containing $50 \mathrm{~mm}$-glucose or $500 \mathrm{mM}$-galactose

Figures given are representative results from a minimum of three separate experiments. Control yeast suspensions incubated in the absence of neutrophils showed at least $95 \%$ viability after 60 min.

\begin{tabular}{llcc} 
Strain & $\begin{array}{l}\text { Carbon } \\
\text { source }\end{array}$ & \multicolumn{3}{c}{$\begin{array}{c}\text { Percentage of viable yeasts } \\
\text { after incubation for: }\end{array}$} \\
\cline { 3 - 4 } GDH 2346* & Glucose & 40 & $60 \mathrm{~min}$ \\
GDH 2346 & Galactose & 51 & 15 \\
GDH 2023 & Galactose & 65 & 31 \\
GRI 681 & Galactose & 36 & 33 \\
GRI 682 & Galactose & 36 & 15 \\
\end{tabular}

* Glucose-grown yeasts of the other strains gave similar results, with percentage viabilities of $13-16 \%$ after $60 \mathrm{~min}$.

bigger response than those grown in medium containing $50 \mathrm{~mm}$-glucose. The ability of different strains of C. albicans to stimulate chemiluminescence is compared in Fig. 3, which shows results obtained with galactose-grown, unopsonized organisms only. The two strains capable of significant cell-surface modification during growth in galactose medium (GDH 2346 and GDH 2023) generated much more neutrophil response than either of the carrier strains, GRI 681 and GRI 682. These strain differences were not apparent when the yeasts were opsonized (results not shown).

\section{Pretreatment of neutrophils with EP}

Since EP isolated from culture supernatants of $C$. albicans GDH 2346 contains the fibrillar surface component produced by this strain in response to high concentrations of galactose 


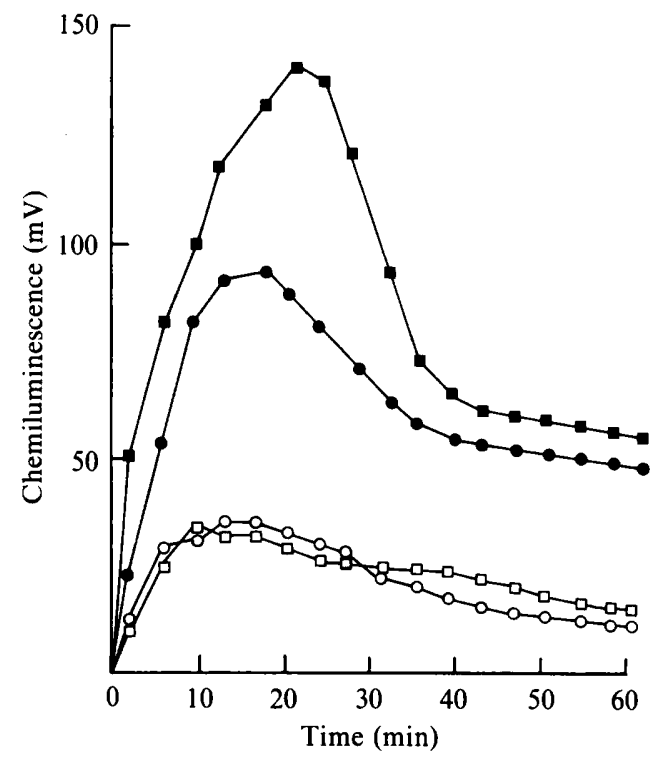

Fig. 3. Luminol-enhanced chemiluminescence emitted by neutrophils stimulated with four strains of unopsonized $C$. albicans grown in medium containing $500 \mathrm{~mm}$-galactose as the carbon source. $\square$, Strain GDH 2346;, strain GDH 2023; $\square$, strain GRI 682; O, strain GRI 681. The data represent mean values from triplicate assays, and are typical of those obtained in at least three separate experiments.

Table 3. Effect of pretreatment of neutrophils with EP on chemiluminescence response elicited by C. albicans GDH 2346

Yeasts were grown in medium containing 500 mM-galactose. Values shown are means \pm SEM from triplicate assays, and are typical of those obtained in at least three separate experiments.

$\begin{array}{cccc}\begin{array}{c}\text { Pretreatment } \\ \text { of yeasts }\end{array} & \begin{array}{c}\text { Pretreatment } \\ \text { of neutrophils }\end{array} & \begin{array}{c}\text { Maximum } \\ \text { peak value } \\ (\mathrm{mV})\end{array} & \begin{array}{c}\text { Total } \\ \text { summed counts } \\ (\mathrm{mV})\end{array} \\ \begin{array}{c}\text { Unopsonized } \\ \text { Unopsonized }\end{array} & \text { HBS } & 479 \pm 9 & 10296 \pm 91 \\ \text { Opsonized } & \text { EP } & 300 \pm 3 & 5131 \pm 96 \\ \text { Opsonized } & \text { HBS } & 558 \pm 5 & 11665 \pm 77 \\ \text { EP } & \text { EPemiluminescence response } & 6897 \pm 440\end{array}$

(McCourtie \& Douglas, 1985), the effect of EP on neutrophil function was investigated. Pretreatment of neutrophils with EP did not significantly affect phagocytosis of opsonized C. albicans GDH 2346 grown on either $50 \mathrm{~mm}$-glucose or $500 \mathrm{~mm}$-galactose. However, pretreatment did result in complete inhibition of intracellular killing of opsonized yeasts. After incubation for $60 \mathrm{~min}$ with EP-treated neutrophils, both glucose-grown and galactose-grown organisms showed $100 \%$ viability; the corresponding figures for yeasts incubated with control neutrophils pretreated with HBS were $8 \%$ and $16 \%$ viability, respectively. Neutrophil activity as measured by chemiluminescence response was also affected by pretreatment with EP. With both opsonized and unopsonized yeasts, EP-treated neutrophils showed a decrease in response of up to $50 \%$ as compared with control, HBS-treated neutrophils (Table 3).

\section{DISCUSSION}

The results of this study demonstrate that synthesis of mannoprotein fibrils by C. albicans in response to high concentrations of galactose promotes phagocytosis of the organism by rabbit 
neutrophils but, at the same time, increases its resistance to intracellular killing. These differences in neutrophil response were observed in experiments with infective strains (GDH 2346 and GDH 2023) which are able to synthesize the fibrillar layer, and not in assays with carrier strains (GRI 681 and GRI 682) which do not have the same capacity for galactoseinduced cell-surface modification. Phagocytosis was greatly enhanced by serum opsonization of the yeasts and differences in sensitivity due to fibril production were detected only with unopsonized organisms. However, increased resistance to intracellular killing resulting from this change in candidal surface composition was observed with opsonized yeasts.

Phagocytosis of opsonized micro-organisms is a process in which recognition between phagocytes and their target is mediated by antibody or complement or both. Neutrophils and macrophages possess receptors for the $\mathrm{F}_{\mathrm{c}}$ moiety of $\mathrm{IgG}$ and for activated forms of $\mathrm{C} 3$ (Stendahl, 1983). In the absence of serum opsonins, on the other hand, phagocytes appear to recognize micro-organisms by lectin-carbohydrate interactions which promote strong attachment but are less efficient at initiating ingestion. Lectin-like interactions are thought to mediate attachment of $C$. albicans to vaginal and buccal epithelial cells via galactose-induced mannoprotein fibrils (Critchley \& Douglas, $1987 a, b$ ). The results reported here suggest that, in the absence of serum opsonins, the same fibrils also promote yeast binding to neutrophils by a related mechanism. Phagocytosis of unopsonized Candida species has previously been demonstrated with mouse alveolar and peritoneal macrophages (Warr, 1980; Kolotila et al., 1987) and there is evidence that yeast-macrophage binding depends on a lectin-like macrophage receptor specific for glycoproteins terminating in mannose or fucose residues (Warr, 1980; Stahl \& Gordon, 1982).

Although fibril production by $C$. albicans enhances non-opsonic phagocytosis, our data show that it also substantially increases yeast resistance to intracellular killing. The candidacidal activity of neutrophils depends primarily on the myeloperoxidase- $\mathrm{H}_{2} \mathrm{O}_{2}$-halide system (Lehrer et al., 1983). However, neutrophils possess a second oxygen-independent mechanism involving the operation of intrinsically antimicrobial proteins and peptides, some of which are highly active against $C$. albicans (Selsted et al., 1985). The fibrillar surface layer of resistant yeasts might exclude or inhibit some or all of these neutrophil components. This would be consistent with a previous finding that yeast cells with this type of surface modification are also more resistant to enzymic digestion by Zymolyase (McCourtie \& Douglas, 1981).

An alternative explanation is suggested by the work of Wright et al. $(1981,1983)$ who have shown that myeloperoxidase-mediated killing of $C$. albicans requires binding of the enzyme to target yeasts and can be antagonized by mannoprotein solubilized from the yeast cell wall. Since the fibrillar mannoprotein layer synthesized by resistant yeasts is released from the cell surface relatively readily (McCourtie \& Douglas, 1981), it too might inhibit candidacidal activity by interfering with the binding of myeloperoxidase to the cell wall proper. In support of this conclusion we have shown that pretreatment of neutrophils with EP, which contains fibrillar material, dramatically suppresses intracellular killing as determined either by a viable count or by the chemiluminescence assay. Although Ballart et al. (1987) have reported a linear correlation between chemiluminescence response and candidacidal activity of neutrophils, some anomalies were observed in the present study. Galactose-induced synthesis of surface fibrils by infective strains resulted in enhanced chemiluminescence (observed with unopsonized organisms) but also increased intracellular survival. However, there did appear to be some correlation between chemiluminescence and the phagocytic activity of neutrophils towards unopsonized yeasts.

Overall, our results indicate that the capacity of some strains of $C$. albicans for cell-surface modification is likely to be an important virulence attribute. Fibril production can be induced in vitro by growth on galactose but may be controlled by a variety of other, as yet undefined factors in vivo. One consequence of this surface change - an increased susceptibility to non-opsonic phagocytosis - could, paradoxically, be disadvantageous to the yeast in tissues such as the renal medulla where opsonic activity is poor (Silverblatt et al., 1979). On the other hand, fibril production would undoubtedly confer significant benefits in terms of adhesion to epithelia (Douglas, 1987) and evasion of phagocytic killing. Release of fibrils from the yeast surface at localized sites of infection could produce high concentrations of mannoprotein with consequent severe effects on phagocyte function. Within the neutrophil, the binding of fibrils to 
myeloperoxidase might permit survival of the yeast long enough to allow germ-tube formation and outgrowth. However, prolonged survival following such an escape mechanism would require that the germ tubes produced under these conditions were just as resilient as the parent yeast (Cockayne \& Odds, 1984).

This work was supported by a grant from the Medical Research Council. We thank Frank Craig for helpful discussions and Donald Tosh for a supply of EP.

\section{REFERENCES}

Allen, R. C. \& Loose, L. D. (1976). Phagocytic activation of a luminol-dependent chemiluminescence in rabbit alveolar and peritoneal macrophages. Biochemical and Biophysical Research Communications 69, 245-252.

Ballart, I. J., Estevez, M. E., Diez, R. A. \& Sen, L. (1987). Comparison of Candida killing activity measured by chemiluminescence and cytomorphological methods in human phagocytes. Journal of Immunological Methods 97, 263-268.

COCKAYNE, A. \& ODDS, F. C. (1984). Interactions of Candida albicans yeast cells, germ tubes and hyphae with human polymorphonuclear leucocytes in vitro. Journal of General Microbiology 130, 465-471.

Critchley, I. A. \& Douglas, L. J. (1985). Differential adhesion of pathogenic Candida species to epithelial and inert surfaces. FEMS Microbiology Letters 28, 199-203.

Critchley, I. A. \& Douglas, L. J. (1987a). Isolation and partial characterization of an adhesin from Candida albicans. Journal of General Microbiology 133, 629-636.

Critchley, I. A. \& Douglas, L. J. (1987b). Role of glycosides as epithelial cell receptors for Candida albicans. Journal of General Microbiology 133, 637643.

Diamond, R. D., Clark, R. A. \& Haudenschild, C. C. (1980). Damage to Candida albicans hyphae and pseudohyphae by the myeloperoxidase system and oxidative products of neutrophil metabolism in vitro. Journal of Clinical Investigation 66, 908-917.

Douglas, L. J. (1987). Adhesion of Candida species to epithelial surfaces. CRC Critical Reviews in Microbiology 15, 27-43.

Kolotila, M. P., Rogers, A. L., Beneke, E. S. \& SMITH, C. W. (1987). The effects of soluble Saccharomyces cerevisiae mannan on the phagocytosis of Candida albicans by mouse peritoneal macrophages in vitro. Journal of Medical and Veterinary Mycology 25, 85-95.

Kozel, T. R. \& Mastroianni, R. P. (1976). Inhibition of phagocytosis by crytococcal polysaccharide: dissociation of the attachment and ingestion phases of phagocytosis. Infection and Immunity 14, 62-67.

LACKIE, J. M. (1977). The aggregation of rabbit polymorphonuclear leukocytes (PMN's): effects of agents which affect the acute inflammatory response and correlation with secretory activity. Inflammation 2, $1-15$.

LeHRER, R. I. \& Cline, M. J. (1969). Leukocyte myeloperoxidase deficiency and disseminated candidiasis: the role of myeloperoxidase in resistance to Candida infection. Journal of Clinical Investigation 48, 1478-1488.
Lehrer, R. I., Selsted, M. E. \& Fleischman, J. (1983). Phagocytosis. In Microbiology - 1983, pp. 273-275. Edited by D. Schlessinger. Washington, DC: American Society for Microbiology.

LeIJ, P. C. J., VAN DEN BarselaAR, M. T. \& VAN FURTH, R. (1977). Kinetics of phagocytosis and intracellular killing of Candida albicans by human granulocytes and monocytes. Infection and Immunity 17, 313-318.

MCCourtie, J. \& Douglas, L. J. (1981). Relationship between cell surface composition of Candida albicans and adherence to acrylic after growth on different carbon sources. Infection and Immunity 32, 12341241.

McCourtie, J. \& Douglas, L. J. (1984). Relationship between cell surface composition, adherence, and virulence of Candida albicans. Infection and Immunity 45, 6-12.

MCCouRTIE, J. \& Douglas, L. J. (1985). Extracellular polymer of Candida albicans: isolation, analysis and role in adhesion. Journal of General Microbiology 131 , 495-503.

ODDs, F. C. (1988). Candida and Candidosis, 2nd edn, pp. 269-273. London: Baillière Tindall.

OKawa, Y., Suzuki, K., Kobayashi, M., Asagi, M., SAKAI, K., SuzuKI, S. \& SuzuKI, M. (1986). Protective effect of acidic mannan fraction of bakers' yeast on experimental candidiasis in mice. Microbiology and Immunology 30, 957-967.

RichaRdson, M. D. \& SMITH, H. (1981). Resistance of virulent and attenuated strains of Candida albicans to intracellular killing by human and mouse phagocytes. Journal of Infectious Diseases 144, 557-564.

Rogers, T. J. \& BALISH, E. (1980). Immunity to Candida albicans. Microbiological Reviews 44, 660682.

SCHERWITZ, C. \& MARTIN, R. (1979). The phagocytosis of Candida albicans blastospores and germ tubes by polymorphonuclear leukocytes. Dermatologica 159 , 12-23.

Selsted, M. E., Szklarex, D., Ganz, T. \& Lehrer, R. I. (1985). Activity of rabbit leukocyte peptides against Candida albicans. Infection and Immunity 49, 202-206.

Silverblatt, F. J., Dreyer, J. S. \& Schauer, S. (1979). Effect of pili on susceptibility of Escherichia coli to phagocytosis. Infection and Immunity 24,218 223.

Stahi, P. \& Gordon, S. (1982). Expression of a mannosyl-fucosyl receptor for endocytosis on cultured primary macrophages and their hybrids. Journal of Cell Biology 93, 49-56.

STENDAHL, O. (1983). The physicochemical basis of surface interaction between bacteria and phagocytic 
cells. In Medical Microbiology 3, Role of the Envelope in the Survival of Bacterial Infection, pp. 137-152. Edited by C. S. F. Easmon, J. Jeljaszewicz, M. R. Brown \& P. A. Lambert. London: Academic Press. Wagner, D. K., Collins-Lech, C. \& Sohnle, P. G. (1986). Inhibition of neutrophil killing of Candida albicans pseudohyphae by substances which quench hypochlorous acid and chloramines. Infection and Immunity 51, 731-735.

WARR, G. A. (1980). A macrophage receptor for (mannose/glucosamine)-glycoproteins of potential importance in phagocytic activity. Biochemical and Biophysical Research Communications 93, 737-745.
Wright, C. D., Herron, M. J., Gray, G. R., Holmes, B. \& Nelson, R. D. (1981). Influence of yeast mannan on human neutrophil functions: inhibition of release of myeloperoxidase related to carbohydrate-binding property of the enzyme. Infection and Immunity 32, 731-738.

Wright, C. D., BowIE, J. U., Gray, G. R. \& NeLson, R. D. (1983). Candidacidal activity of myeloperoxidase: mechanisms of inhibitory influence of soluble cell wall mannan. Infection and Immunity $\mathbf{4 2}$, 76-80. 